\title{
A Spatial Framework for Managing Sewer and Water Networks Using Sensor Networks: A Case of the University of Zambia
}

\author{
https://doi.org/10.3991/ijes.v8i1.13983 \\ Gabriel Chibuye ${ }^{(凶)}$, Jackson Phiri, Faustin Banda \\ The University of Zambia, Lusaka, Zambia \\ gab.chibuye@gmail.com
}

\begin{abstract}
The University of Zambia like any public institution has a lot of infrastructure which require maintenance and management. There's however uncertainty of the utility lines locations and their depths. This causes destruction of water pipes and sewer lines when undertaking new constructions or any excavations. The lack of accurate location of underground and unupdated lines makes maintenance, management and planning of the utilities very difficult. Therefore this study aimed to build a framework for Managing Sewer and Water Networks Using Sensor Networks at the University of Zambia. The Resident Engineer's office only has some old scanned pdf sketches of both sewer and water networks. The field engineers locate most lines and other facilities using memory and experience. The methodology involved understating the existing operations of the Resident engineer's office to ascertain the user needs. These needs formed the basis of the research, the development and design of the prototype of the Webbased Framework. Data Collection tools included Records (old maps) and Secondary Data (satellite images), Field Observations, Interviews and field Surveys. A presurvey (Reconnaissance Survey) was done to have an idea of the existing infrastructure and a more accurate survey was done using GPS GNSS equipment. The raw data was processed and GIS software was used to merge the collected datasets and the existing data. Georeferencing of existing maps and the satellite images was done using the GPS field data in ArcMap. New shapefiles were created from the point data from the survey and from digitising the existing scanned maps. New maps of the water and sewer networks (using the new shapefiles) and satellite imagery were created. A 15 digit coding system was created and was used to assign unique identification numbers and extra attribute information to the water and sewer network shapefiles. A QR code was generated for each node and the serial number recorded. Tagging was done using the QR code for each structure. All the shapefiles were loaded into a PostGreSQL spatial database and were used as input in the Web GIS application. The web application had some tools imbedded in it including; query, measure, add point/vertex, zoom, view, search and identify. Using internet of things (IOT) technology, water level sensors were placed on some critical manholes to help with the monitoring of the sewerage network. The system can therefore be used for identification of any infrastructure by scanning the QR code and a map showing the structure is seen online by the field
\end{abstract}


technicians. Monitoring of the sewer system can be done using the sensors and ultimately the framework will ease the management of the water and sewer systems at the University of Zambia.

Keywords - GIS, WEBGIS, Sensors, Internet of Things, Coding, tagging, QR Codes.

\section{Introduction}

The University of Zambia is rapidly expanding as observed from the new developments all around campus [1]. The growth requires more land and development of university infrastructure. Utilities such as water, sewerage, electricity and telecommunications are essential for the smooth running of any public institution. The university utility spatial information management is therefore one the key areas of focus that requires attention and adequate use of tools for its maintenance. In particular, water and sewerage provide inevitable sustenance to life and a means of discarding waste water respectively and as such these utilities need to be managed well.

Most of the water utility spatial information used in managing the university facilities are primarily paper based maps. These hardcopy maps and documents have not been updated in a very long time hence are inaccurate. These hardcopy maps are no longer appropriate for real time decision making because they are unable to act in response to changing circumstances. The field technicians currently locate most lines and other facilities using memory and experience. Consequently, there is need to introduce better systems that are more efficient in spatial data organization, manipulation and visualization.

The aim of the study was therefore to build a spatial framework for managing the existing sewer and water networks at the University of Zambia. The first objective was to conduct a baseline study of the existing sewer and water networks. The second objective was to design a framework for the GIS sewer and water networks integrated with sensors based on the findings in the first objective. The final objective was to develop a prototype based on the framework developed in the second objective using the web, mobile and sensing technologies.

The Research Questions formulated were in line with each objective. For objective one the research question was: Where are the water and sewer networks located and how are they currently identified around the University? In objective two the research question was: Can a framework be designed for the findings in the first objective to monitor, manage and integrate the utility system with sensors? Finally the third research question was: How can a prototype of the framework designed in the second objective be developed?

A Web-based GIS or WebGIS application was used to develop a spatial framework. WEBGIS is a powerful mapping and analytical functionality expressed within a web browser. The web application had some tools imbedded in it including; query, measure, add point/vertex, zoom, view, search, identify and update. Using 
internet of things (IOT) technology, water level sensors were placed on some locations to monitor some manholes of the Sewerage network. Utility coding and tagging was done using QR code. The code was used to uniquely identify all the structures. The web application will also be accessible using a mobile application. A user with a mobile device and QR Code reader can scan the code on any tag to know which structure is being looked at by clicking the link which would open a web map app where more details can be obtained. For the Web app the user can view the whole network immediately the page is opened. In both mobile and web browsers, there will be login requirements before any user can proceed.

\section{$2 \quad$ Literature Review}

The literature reviewed involved looking at the various geospatial and other relevant technologies that could be of use in water and sewer networks. These included aspects of Land Surveying, Traditional GIS and Mapping, Web Mapping, Spatial Database, QR Code technology and Internet of things technologies.

\subsection{Geographical Information Systems (GIS)}

Geographical Information Systems (GIS) technology offers combined power of both geography and information systems an ideal solution for effective management of water and sewer utility infrastructure. The effective management of water utility network can be possible by proper representation and analysis of network data [2]. The most important applications of GIS for water utility management are mapping, monitoring, modelling, infrastructure, planning, maintenance, water conservation and response to emergencies [3].

Much recent attention in GIS has been focused on developing GIS functionality in the Internet, Worldwide Web, or a private intranet, which is sometimes termed WebGIS. It hosts traditional GIS functionalities on the internet web, coupled with the powerful ability to integrate information and tools from multiple sources.

\subsection{Web development}

Web Application development uses both off the shelf software packages (ESRI DesktopGIS) and Free Open Source Software (FOSS) i.e geospatial platform for building WebGIS applications across web browsers, desktops, and mobile devices. The software that may be adopted include database server, a front-end comprehensive database design and management system [4], a map server to link the database to the client and acquires and processes requests coming from the user and return output results. An app for displaying dynamic map data in web browsers from multiple sources [5]. In addition an open source sever implementation of the Java Servlet, JavaServer Pages, Java Expression Language and Java Websocket technologies [6]. 


\subsection{Internet of Things}

Internet of Things is the system of physical objects or things hooked up with hardware, software, sensors, and system connectivity which empowers these objects to gather and alternate information. IoT makes use of different kinds of protocols to work with exclusive objects [7].

\subsection{Wireless sensor networks}

Wireless Sensor Networks are part of the perception layer found in the Internet of things [8]. Wireless Sensor Network requires multiple nodes to form a network [9]. The sensor nodes continuously or at set intervals sense data from the environment and send the data to the sink node [10].The sink node collects the data from sensor nodes for viewing locally and sending for storage. The data from the sensor nodes can be accessed remotely over the Internet or other means by users [11]. The wireless sensor networks provide better methods of monitoring environmental conditions than manual methods [12]. Wireless Sensor Networks are now a reality with applications in Smart Grids, Smart Environments and machine to machine communication.

\subsection{SASPlanet software}

SASPlanet is a program designed for viewing and downloading high-resolution satellite imagery and conventional maps submitted by such services as Google Maps, DigitalGlobe, Kosmosnimki, Yandex.Maps, Yahoo! Maps, VirtualEarth, Gurtam, OpenStreetMap, eAtlas, Genshtab maps, iPhone maps, Navitel maps, Bings Maps (Bird's Eye) etc., but in contrast to all these services all downloaded images will remain on your computer and you will be able to view them, even without connecting to the internet. In addition to the satellite-based maps you can work with the political landscape, combined maps and maps of the Moon and Mars [13].

\subsection{Tagging}

According to Amazon Web Service [14] Tags provide identification and classification resources by the association of descriptive metadata, for example, application identifier, environment, or owner. Each tag consists of a key and a value, both of which are user-defined strings. Naming of the features in this study was done in preparation for tagging and accurate field survey.

\subsection{Bar codes and $Q R$ codes}

A barcode, consisting of bars and spaces, is a machine-readable representation of numerals and characters [15]. Today, stripes as shown below on packages of products sold at supermarkets, convenience stores and other stores are ubiquitous. These are barcodes. A barcode consists of bars and spaces of varying width that can be read with an optical barcode scanner. 
Quick response code ( $Q R$ code) is a type of two-dimensional (2D) barcode that can be read using a QR barcode reader or camera enabled smartphone with QR reader software.
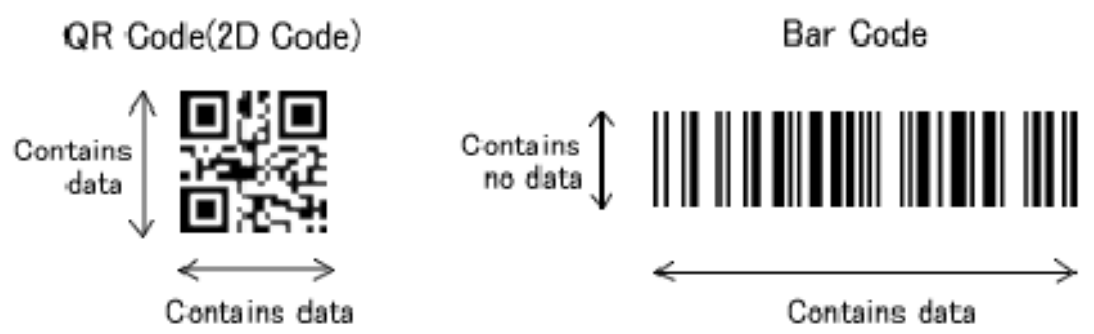

Fig. 1. Comparison of QR code and Bar code

A QR code is able to carry information in both the vertical and the horizontal direction, which is why it is called a 2D barcode [16]. This is why a QR code holds a significantly larger capacity of data. It can encrypt numerous sorts of information or data such as binary data, multimedia data, symbols and control codes [17]. It can encode a website URL, a YouTube video URL or any social media links, geocoordinates, email addresses, email message and so on [18]. QR Code is quicker to read than other two-dimensional code, because it comprises of three large square shapes in the corners that are used for position detection [19].

\subsection{Related works}

Most of the related works that have been done combine various technologies to develop frameworks and prototypes. However not much has been done to combine utility mapping with sensors and addition of the QR Codes to the web applications.

Nickolas Okello [20] developed a GIS based decision support tool for effectively and efficiently managing the water utility networks at the Copperbelt University using PostgreSQL/PostGIS, QGIS, GeoServer and GXP template built on GeoExt and OpenLayers. The goal was to have a centralized system with easy access to accurate and updated information on water utility network spatial information throughout the university by means of the web. In his findings he sufficiently demonstrated the application's ability to act as a decision support tool for the end-users and decision makers in the management of water utility networks at the university.

Zambia's agricultural sector through Food Reserve Agency (FRA) while still underdeveloped faced many challenges that ranged from marketing, spoilage, infestations, and theft at site, spillage and storage among others. The methods used by FRA in their business processes were largely manual as there were no systems in place. In order to help curb these problems, Chihana [21] proposed and developed novel methods that could be used to sense real-time warehouse intrusion and grain tracking within the FRA circulation. The IoT based prototype model made use of the APC220 transceiver, GSM, GPRS, RFID, PIR and cloud storage. To curb theft of grain at storage points, the system used motion sensing through the use of PIR 
sensors, wireless radio communication module and the GSM/GPRS technologies such that when anyone comes in the range of PIR sensor, then the sensor will send a logic signal to the microcontroller. Lastly, the RFID combined with GSM and Arduino microcontroller responsible for grain tracking. From the results obtained in the experiment conducted it was believed that once this technology was adopted, thefts would be reduced and grain management in the FRA satellite Depots dotted around the country would improve.

Chilela [22] developed a WebGIS at University of Houston in United States of America. It was capable of saving, organizing, and geo-spatializing information from all over the campus and facilities. The WebGIS could process data and manipulate devices connected to the internet using concepts and tools of Internet of Things and provide the number of people inside of buildings. The information about the number of people inside of buildings was a new technology known as smart door. In case of a public business building (bank or shopping for instance), the WebGIS was capable, for example, of showing the average time that a client would spend in that building to be attended. In addition, the study provided a mobile application to allow users to interact with smart campus and campus facilities and to facilitate access to basic information about public transportation and data sensors which had been placed in various locations around campus.

Mwansa and Phiri [23] proposed a model for the inventory system based on Quick Response (QR) and cloud computing for real-time capture of grain bags brought in by farmers at the satellite depot for the Food Reserve Agency (FRA). The government of Zambia supplied farming input to local farmers and bought the grain back from the farmers. The study looked at part of the buying process which required the movement of grain from the local farmer to the government. The proposed system first required tagging the grain bags then capturing the details of the farmer and attached this to the grain bags. Their proposed model based on cloud technologies was integrated with the mobile application used to read the QR code attached to the grain bags. These details were then linked to the details of the farmer in the database. These captured data regarding the farmer and grain bags supplied at the satellite depot were made available to the decision makers in real-time. The results of the study showed that the proposed model would help to address a number of challenges that the current system had been facing. These included accelerated process of paying the local farmers supplying grain to the government which used to take months. It would also help to give the grain stock statistics in real time per region and the country at large. This model would be very useful for most developing countries in managing their grain.

In order to introduce modern warehousing, improve upon the storage of grain and grain marketing business processes for the Food Reserve Agency in Zambia, Chibuye [24] developed a prototype of a remote sensor network and built as a proof of concept for a much wider deployment using cloud computing and the internet of things concept. It was determined that a wireless sensor network would aid the Food Reserve Agency in analytics, timely action and real-time reporting from all its food depots spread-out throughout Zambia. Google's Android Things Platform was used in order to achieve the objectives. Advantages of Android Things over traditional platforms 
that had been used to develop wireless sensor networks were looked into and presented in this paper.

From rainfall data, patterns and topography Fujistsu Technologies [25] were able to come up with the best locations for placing sensors in a sewer network. They developed a technology that uses ICT for low-cost detection of early signs of sewer system overflows in order to mitigate damage in cities stemming from torrential downpours. The technology for determining the locations and number of manholes where sensors should be installed, based on an analysis of the time required for water to flow from upstream pipes to downstream locations in accordance with land topography and the shape and length of sewer pipes, which makes it possible to track and predict the overall flow through a sewer system using only about one-fifth as many sensors.

Mutale [26] proposed a document archiving system which would integrate barcoding, time stamping and mobile technologies to improve on the achieving and retrieval processes. The study began with the baseline study in an effort to establish the challenges faced by institutions of learning in document archiving. The study was based on the University of Zambia. The results from the study indicated that $70 \%$ of the offices used the manual box file system in Document achieving. They also lacked storage space for box files with $80 \%$ having difficulties in retrieving old documents. Based on this study, Mutale designed and implemented a document archiving system. The system was developed in C\#. It had time stamp integrated with short messaging system (SMS) for reminders and barcode which was electronically stapled on the soft copies before being archived to improve on the identity of the document.

The study used some of the methodologies from the various works outlined and the framework developed involved combining some of these methodologies.

\section{$3 \quad$ Methodology}

The methodology involved the understanding of the spatial distribution of the utilities installed cross campus. This involved collection of data from the Resident Engineer's Office and interviews of key personnel. The designing of the framework was done based on the literature that was reviewed. The prototype has been designed and developed based on the framework and it will be used by the Resident Engineer's office for monitoring, management and planning.

Equipment and Materials used; GPS GNSS RTK Set (High Target V30), Total Station, Tablet PC, Laptop, arduino kit, Water level Sensors and accessories, tags. Software; GPS Essentials, Ht Target Software, Microsoft Office (Word, Excel, Access, Powerpoint), Mapping Tools (ArcGIS, QGIS, Bing Maps, SASplanet), Automation Tools (Web and Web Mapping Development Apps, Database Development tools, Sensor integration tools).

The figure 2 below shows a summary of the procedures involved in the methodology leading to the prototype development. 

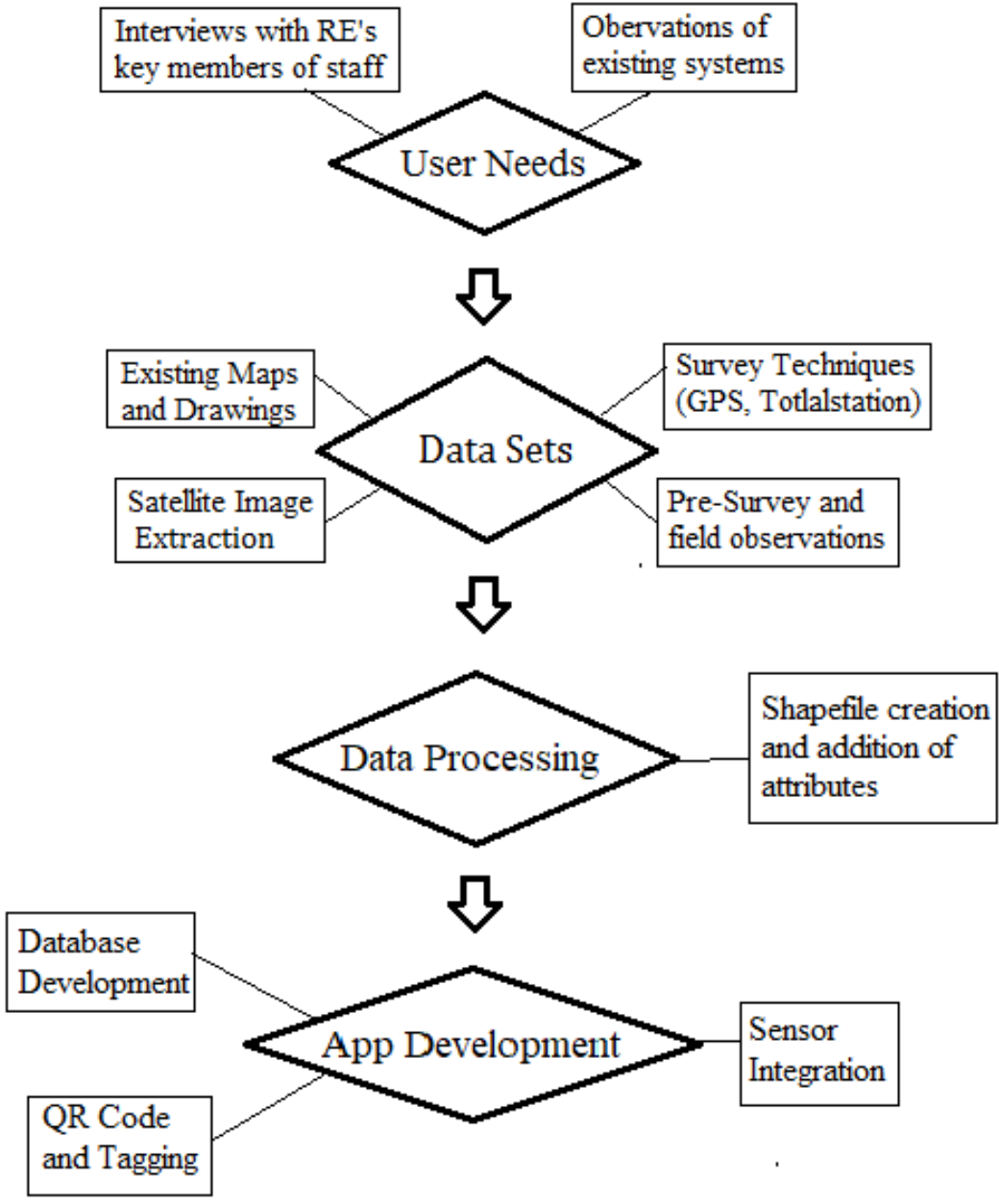

Fig. 2. Methodology workflow

\subsection{User needs}

The resident engineer's office was engaged to find out what their current system for the management and maintenance of the utility was. These needs formed the basis of the research and the development and design of the prototype had this in mind in order to be able to answer or improve on the identified user needs.

\subsection{Data collection}

The data collection began after the research problem was defined and research design/ Plan had been formulated. Multiple data collection methods were used. Data 
Collection tools included Records and Secondary Data, Field Observations, Interviews and field Surveys and Maps.

Records and Secondary data - included hard copy maps, scanned maps, electronic files (AutoCAD drawings), the sample data is shown in figure 3. Unstructured interviews where adopted and using purposive sampling technique. Information was obtained from key members of staff from the resident Engineers office. The members of staff included; The Resident Engineer, The Water and Sewer Superintendent, The sewer System technician and the water system technician. The assessment of user needs was based on these interviews. The figures 3 show the existing water and sewer layouts respectively.

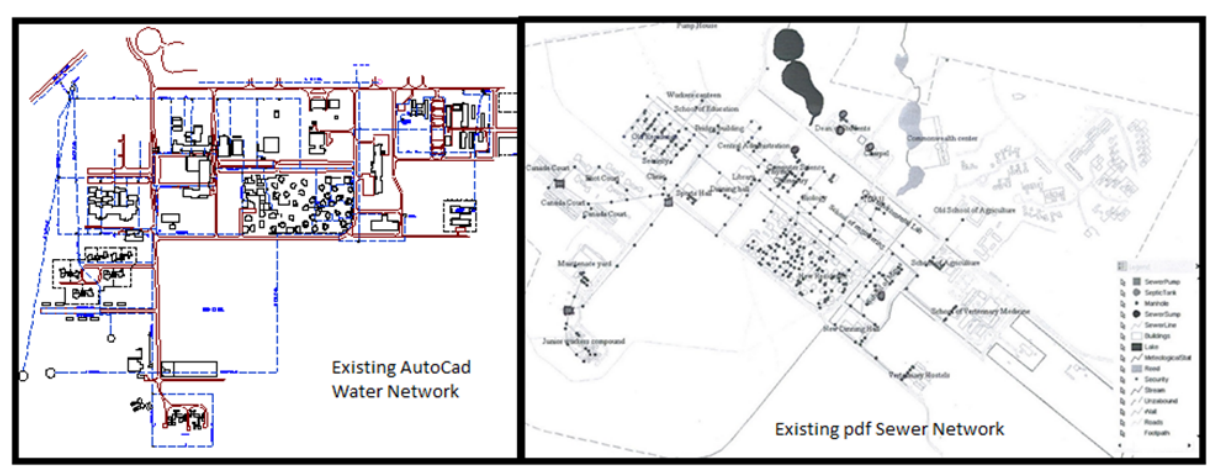

Fig. 3. Existing water network (AutoCAD Drawing) (left), Scanned Sewer Network (right)

\subsection{Reconnaissance and field survey}

Field Observations were done while interviewing the technicians and helped with the reconnaissance field survey. A reconnaissance (Pre survey) field survey was carried out to verify the Resident Engineer's Maps. Each manhole, sewer line, water line, water valves, fire hydrant, water tank and borehole was identified and its location collected using Google maps and GPS essentials android mobile applications. A Samsung tab E was used. The locations were to an accuracy of $1 \mathrm{~m}$. The survey was useful as it gave an idea where each feature was located hence helped in preparing for the method and equipment to be used when carrying out a more accurate survey. Old obsolete structures were identified and new structures were picked to update the exiting maps.

The name and some attribute data were added for each feature. The geolocation was activated on the tablet to help show the condition and general outlook of each feature from the photo by location. All the field findings were later verified with the resident Engineer's office by providing new map showing all the interconnections and having the resident Engineers technicians verify the connections and all attribute information related to each feature.

Field Survey was done based on the field observations. The physical measurements to collect positions of various features using survey tools such as Global Positioning Systems (GPS), Total Stations, Electronic/ automatic levels was done. The GPS RTK 
system was used for getting location data for most of the features though a total station was used where the GPS signal was poor for example under trees or very close to buildings. The amount of time spent in undertaking the field survey was greatly reduced due to the help of the reconnaissance survey.

\subsection{Data processing and shapefile creation}

The raw primary data obtained using Land Surveying techniques was cleaned converted to shapefiles and used to georeferenced other datasets (Satellite image, Sewer Network and Water Networks). This Field Survey data was processed prior to its entry in a GIS Software and was combined with the rest of the data. Images were georeferenced using the surveyed field data, Digitizing was further done to create new shapefiles of roads, buildings, water lines, Sewer lines, water tanks, fire hydrants and all other existing infrastructure.

\subsection{Naming and tagging system}

Naming of the features in the study was done in preparation for tagging after the shapefiles were created for each feature. There were basically two types of features i.e. nodes and lines. Nodes included point data like manholes, water tanks, water valves; fire hydrants. Lines included line features which were sewer lines and water lines. Each feature was given a unique code, line segments were also given codes including their starting point and finishing point. The tagging system that was used had 15 digit code e.g. for a manhole RE01MHS10000001;

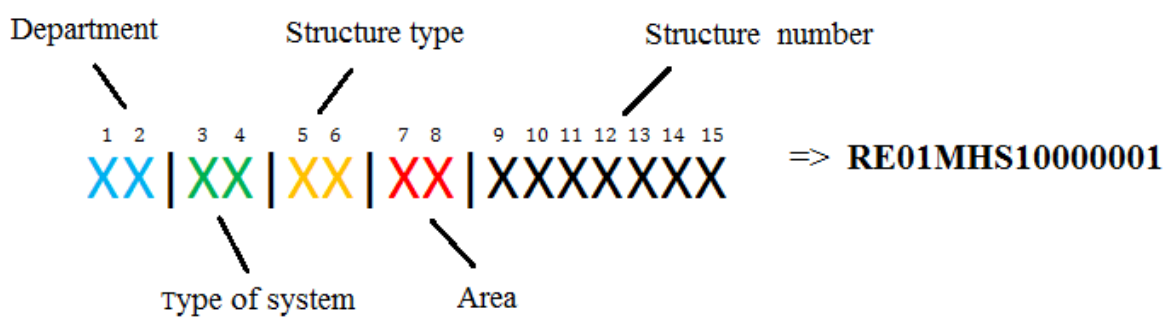

Fig. 4. 15 digit serial number

\subsection{Database design and development of the framework}

The spatial databases designed and developed for this study included layers of water supply lines, sewer lines, fire hydrants, valves, water tanks, roads, buildings generated from digitizing existing maps, satellite images and from GNSS surveys. Fields and attributes were created for each layer and the tag names were used as primary keys. All the shapefiles were cleaned and the fields well labelled in preparation for their entry in the spatial database. The spatial database that was used was PostGreSQL. From the data collected in objective 1, point, line and polygon 
features were created. The 15 digit code was formulated and each feature was given a unique serial number which was scanned to generate QR Codes.

The created shapefiles were loaded into the PostgreSQL spatial database and using PostGIS the dataset were connected to geoserver for uploading on to the web app. The layers were customized and functionalities were added using open layers and JavaScript library tools.

\subsection{Development of the web GIS prototype}

In the prototype development, the structures were tagged with the generated QR Codes. A user with a mobile device and QR Code reader could scan the code on any tag to know which structure is being looked at by clicking the link which would open a web map app where more details can be obtained. For the Web app the user can view the whole network immediately the page is opened. In both mobile and web browsers, there will be login requirements before any user can proceed. For some manholes, water level sensors will be installed to monitor the water level. The sensor will send data to the arduino kit which will send data to the web app as an alert. Figure 5 shows a pictorial summary of the prototype.

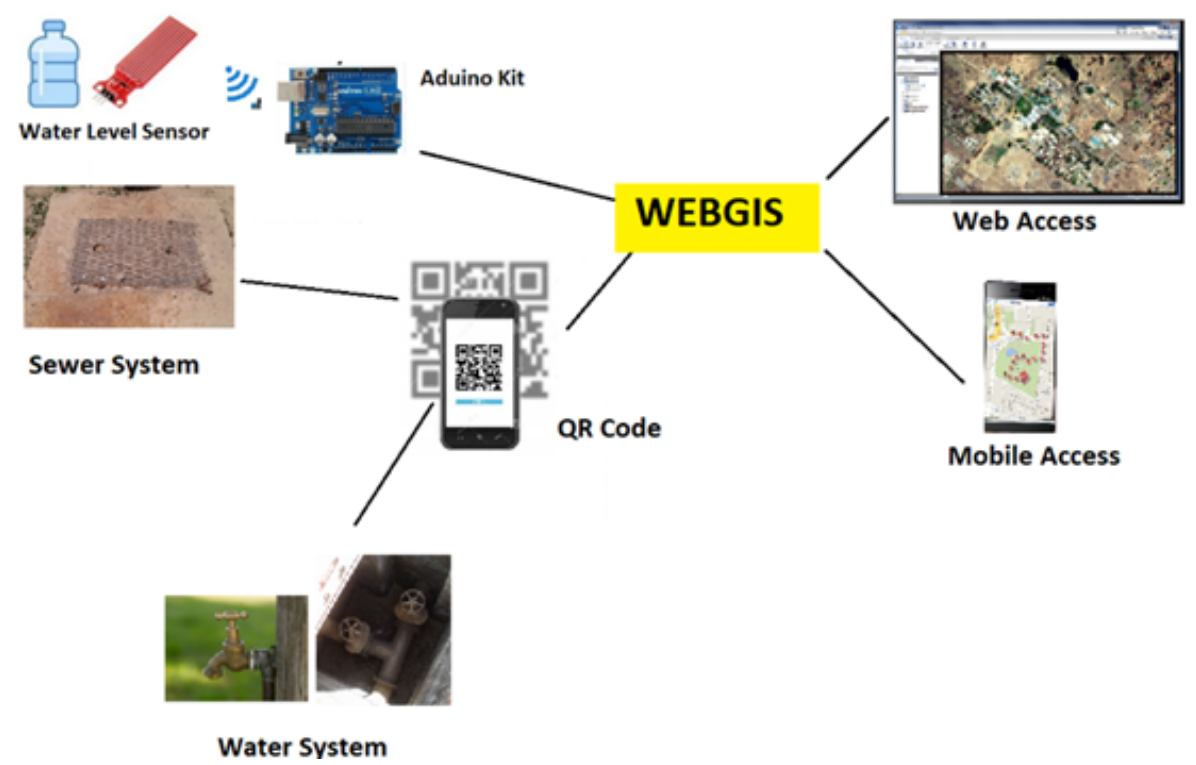

Fig. 5. Summary of the proposed prototype 


\section{$4 \quad$ Results and Discussion}

\subsection{Identifying user needs}

The user assessment needs helped to understand the operations and what the Resident Engineer's office needed. The framework was then based on the final output that would help the department in their operations. The following needs where identified;

- Need for a way to identify all the infrastructure both on site and in the office

- Need to keeping track of the maintenance and maintenance history of all infrastructure

- Need to monitor the conditions of infrastructure

- Need for more accurate and better way of visualizing the infrastructure

\subsection{Data collection and processing}

The data collection began after the research problem was defined and research design/ Plan had been formulated. The raw primary data obtained using Land Surveying techniques was cleaned converted to shapefiles and used to georeferenced other datasets (Satellite image, Sewer Network and Water Networks).

The various data collected were processed in a GIS software (arcMap and QGIS) and more datasets were created for different features. The field survey data was first processed in order to be used in a GIS software. The images were georeferenced and new shapefiles were created with the layers overlaid on the existing maps to help with updating the water and sewer networks.

The pre survey was done using the tablet greatly reduced on the amount of time that could have been spent in the field looking for features had this not been done first. The GPS RTK system was used for getting location data for most of the features though a total station was used where the GPS signal was poor for example under trees or very close to buildings. The control points used were survey points that are already connected to the national system in UTM arc 1950 Zone $35 \mathrm{~S}$ and were converted to the WGS84 coordinated system. Features that were picked included all the sewer and water related structures, Road center lines and some existing buildings and other features. The raw data data was recorded in the GPS Rover controller, downloaded and loaded it into Microsoft Excel. The data from the GPS controller was cleaned up in Microsoft excel to make it in a format compatible with drafting and mapping software.

Georeferecing and Digitising: QGIS and Environmental Systems Research Institute's (ESRI) DesktopGIS - ArcMap were both used for desktop mapping for the research study. Most shapefiles were created in ArcGIS and later exported to the PostgreSQL/PostGIS database using QGIS. QGIS was used for displaying, querying, updating and analysing data directly from the database in Postgres / PostGIS.

Georeferencing a raster to a vector method in arcGIS 10.1 was used to georeference the raster data using the vector data obtained from GPS GNNS survey. 
The raster data included; the Bing image extracted from SASplanet, the scanned sewer network and the water networks. Road junctions and corners of some buildings that were clear on the image and had been picked on the ground during the survey and were used as control points to reference the images. A minimum of four control points were used for each image. The final RMS Error was computed from the link table. Figure 6 shows the georefencing process and a georeferenced image. All the data was merged one coordinate system WGS84. Shapefiles were created for each feature and using the surveyed data, points were connected following the respective Image maps from the RE.
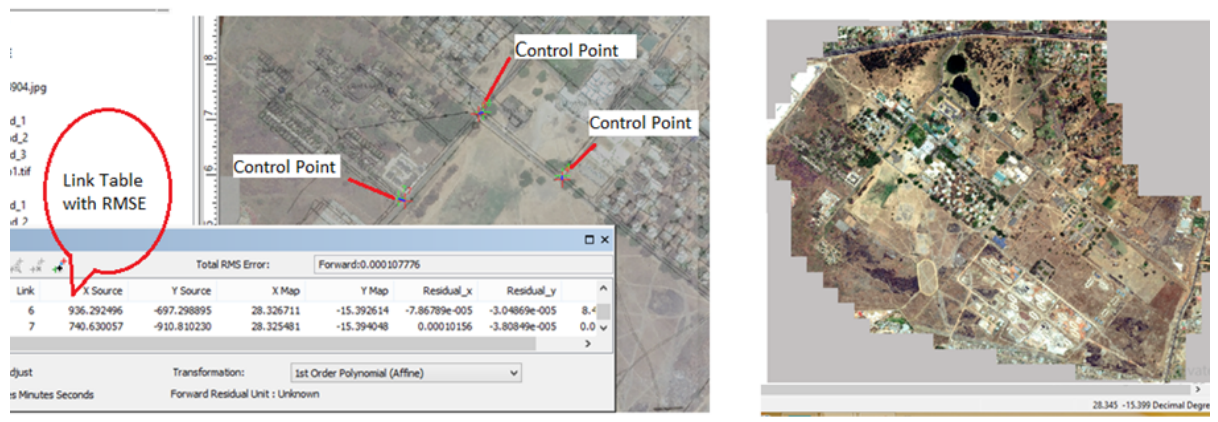

Fig. 6. Georeferenced control points and link table (Left), Georeferenced image in WGS84 (Right)

After Georeferencing of both the Satellite image and the jpeg sewer layout as well as water network in arcMap, the sewer map was overlayed on the SAS map image. Its transparency was increased in order to view the SAS image below in figure 7. The same procedure was done for the water network. 


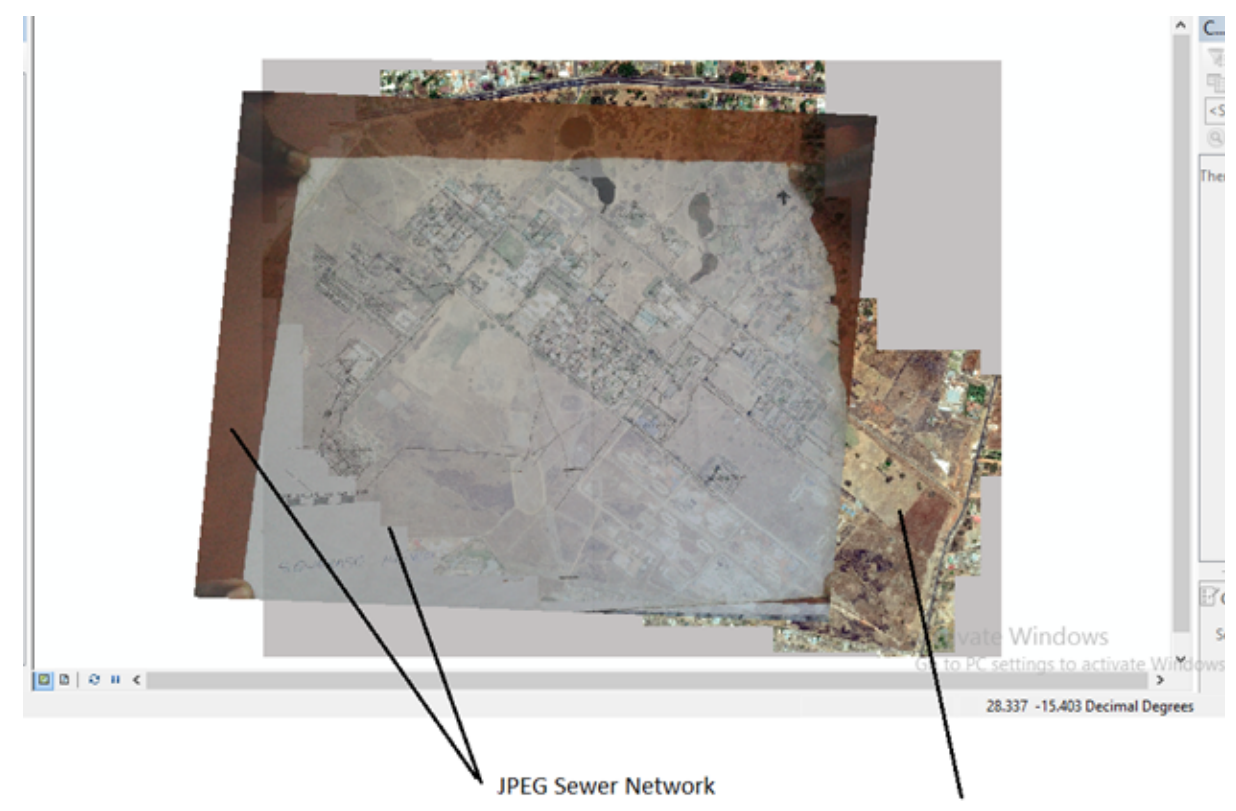

Fig. 7. Satellite Image and Sewer network

The existing buildings, roads and other significant features were digitised to produce shapefiles for each feature.

Addition of attributes: More attribute data was added for each layer obtained in objective 1 for both water and sewer networks. There were basically two types of features i.e. nodes and lines. Nodes included point data like manholes, water tanks, water valves; fire hydrants. Lines included line features which were sewer lines and water lines. Each feature was given a unique code, line segments were also given a code including their starting point and finishing point.

Production of new sewer and water networks maps: A new map was produced with all the existing features, as well as the sewer and water networks produced with the updated shapefiles from the field survey. With the appropriate codes and name tags and other information in the attribute tables. Figure 8 shows the layout of the Sewer system while figure 9 shows the map of the layout of the water system. 


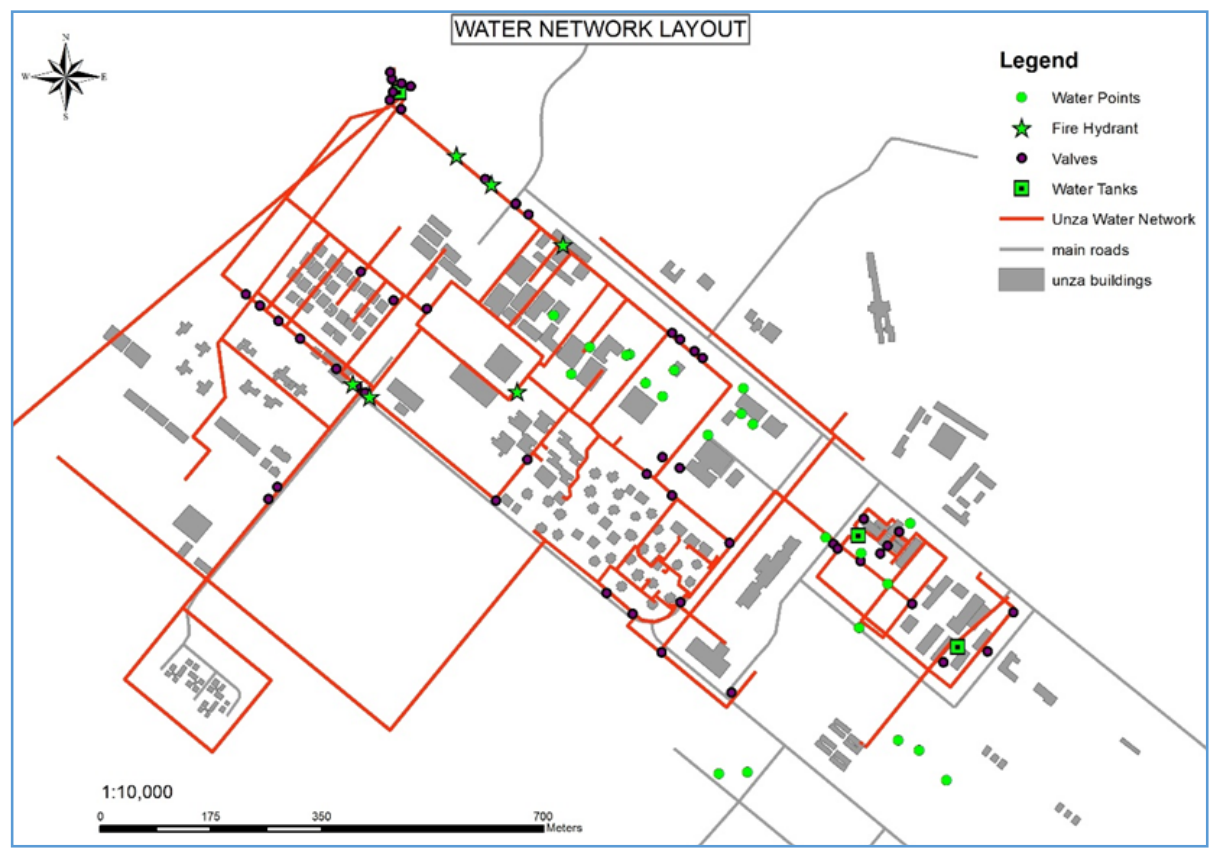

Fig. 8. Updated Water Network

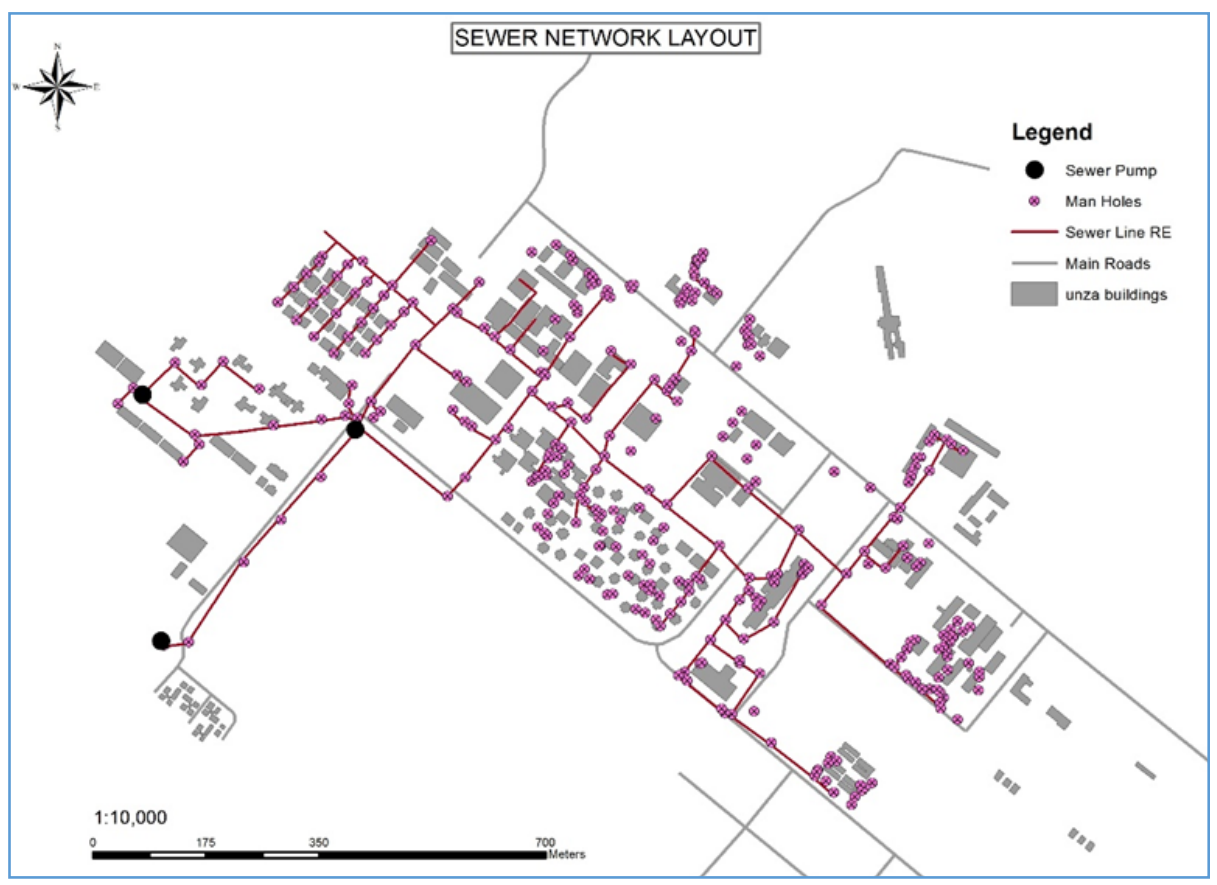

Fig. 9. Updated Sewer Network 


\subsection{Naming and tagging system}

Naming of the features was done in preparation for tagging after the shapefiles were created for each feature. Each feature was given a unique code. The tagging system that was used had 15 digit code e.g. for a manhole RE01MHS10000001.

$\begin{array}{lllllllllllllll}1 & 2 & 3 & 4 & 5 & 6 & 7 & 8 & 9 & 10 & 11 & 12 & 13 & 14 & 15\end{array}$

\section{R E 01 M H S 10000000001}

1 and 2 - Resident Engineer's Department RE

3 and $4-$ Type of system, 01 is Sewer system, 02 is Water System

5 and 6 - Representing the structure type MH is manhole. WL is Water Line, SL is Sewer Line etc.

7 and 8 - Represents the area where the structure is. The areas in UNZA have been divided into four parts hence the third digit ranges between S1 and S4.

9 to 15 - The actual number of the structure e.g. 0000001 is number one.

Table 1 is a summary of the possible codes of the various features (manholes, water tanks, water valves, fire hydrants, water pipes, sewer lines (pipes).

Table 1. Summary of the possible codes of the various features

\begin{tabular}{|c|c|c|c|c|c|}
\hline Digit & 1 and 2 & 3 and 4 & 5 and 6 & 7 and 8 & 9 to 15 \\
\hline Name & Department & $\begin{array}{l}\text { Type of } \\
\text { System }\end{array}$ & Structure & $\begin{array}{l}\text { Area code } \\
\text { from figure } 13\end{array}$ & $\begin{array}{l}\text { Actual } \\
\text { number of the } \\
\text { structure }\end{array}$ \\
\hline $\begin{array}{l}\text { Possible } \\
\text { Codes }\end{array}$ & $\begin{array}{l}\mathrm{RE} \text { - Resident } \\
\text { Engineer }\end{array}$ & $\begin{array}{l}01-\text { Sewer } \\
\text { System, } 02- \\
\text { Water } \\
\text { System, } 03 \text { - } \\
\text { Storm Water }\end{array}$ & $\begin{array}{l}\text { SL-Sewer } \\
\text { Line, } \\
\text { MH - Man } \\
\text { Hole, } \\
\text { WL - Water } \\
\text { Line, } \\
\text { WT - Water } \\
\text { Tank, } \\
\text { FH - Fire } \\
\text { Hydrant, BH } \\
\text { - Bore Hole, } \\
\text { SP - Septic } \\
\text { Tank } \\
\text { WV - Water } \\
\text { Valve }\end{array}$ & $\begin{array}{l}\mathrm{S} 1, \mathrm{~S} 2, \mathrm{~S} 3 \\
\text { and S4 }\end{array}$ & $\begin{array}{l}000001 \text { to } \\
999999\end{array}$ \\
\hline
\end{tabular}

\subsection{QR code generation}

The codes were input into an online QR code Generator which produced png images of each QR code. The QR codes stored the unique ids for each node that in turn would have a link to the web map once a user clicks it. The figure 10 shows an example of some manholes and sewer lines, generated QR Code. 


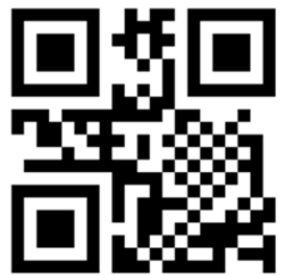

Sewer Manhole No. 1

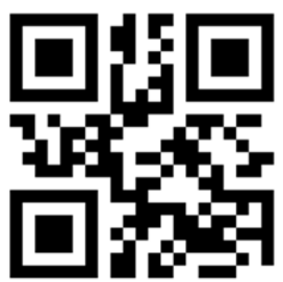

Water Manhole No. 5

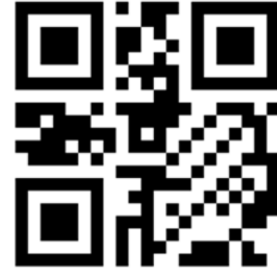

Sewer Manhole No. 2

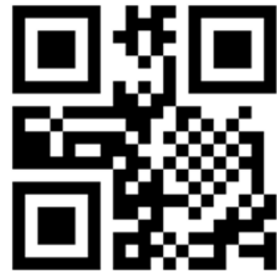

Sewer Manhole No. 10

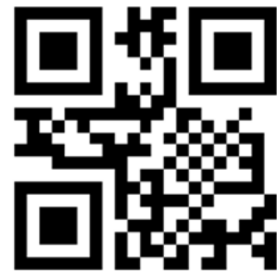

Sewer Line No. 1

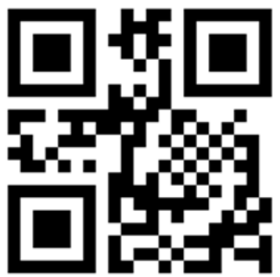

Water Manhole No. 100

Fig. 10.Examples of some generated QR Codes

Tagging of the QR Codes was done for each node. The tags were stuck on manholes such that they could easily be seen and read. The tags were labelled with a QR Code matching the codes in figure 10. The special QR code assigned in the system would be used for identification by simply reading off the code using a phone with QR Code reader, one would be able to locate where a particular manhole is on the map and all the attributes associated with it.

\subsection{Webmap development}

Based on the compiled data, Database design was initiated. Database design, Development and implementation were the phases carried out in the process of ensuring that the resulting database met user requirements, had efficient data structures and retrieval mechanisms, normalization principles, support for data sharing, multi-user access through the WebGIS portal, easy editing, update and maintenance.

The GIS based decision support tool was built around OGC compliant software identified from the literature reviewed. The focus of the analysis was on PostgreSQL and Geoserver which formed the core phases of the development of the GIS based decision support tool.

\subsection{Spatial database design}

PostgreSQL was selected as the open-source database server to support geographic objects and functions such as coordinate systems, projections, etc. Shapefiles were 
exported to the PostgreSQL/PostGIS database. The default PostgreSQL installation is not capable of supporting operations on spatial data. It manages data in an objectrelational database management system.

PostGIS, an extension, provided the added functionality to handle spatial queries and operations after running the command 'CREATE EXTENSION postgis' in SQL Editor. This was used to import all the shapefiles for the water and sewer lines, water network valves, fire hydrants, manholes, water meters, buildings, roads, streams, reservoirs, boreholes etc. QGIS was used for displaying, querying, updating and analysing data directly from the database in Postgres/PostGIS. The figure 11 shows the screenshot of the postgreSQL with the datasets loaded for the existing infrastructure.

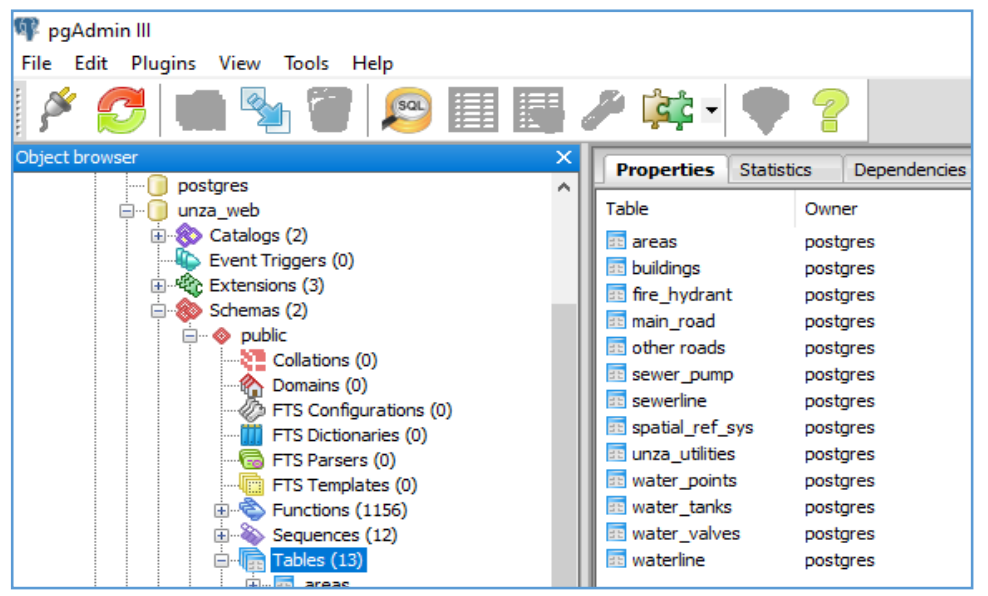

Fig. 11.Screenshot of the PostgreSQL with the UNZA existing infrastructure loaded

The coordinate system was then manually assigned for all the imported shapefiles. The coordinate system used was WGS84. Client application access to the spatial database was through SQL statements. The Query Tool in SQL Editor was used to execute SQL commands for converting the GIS layers in the PostgreSQL/PostGIS database to GeoJSON, KML and text format.

\subsection{Mapserver}

GeoServer was selected as the map and feature server for sharing, analysing and editing geospatial data from the PostgreSQL/PostGIS database. GeoServer supplies geospatial information using standard protocols (WMS, WFS and WCS) established by the Open Geospatial Consortium. These are explained below:

The Web Feature Service (WFS) supports requests for geographical feature data with vector geometry and attributes.

The Web Map Service (WMS) supports requests for map images and other formats generated from geographical data. The Web Coverage Service (WCS) supports requests for coverage data i.e. rasters. 
The default password was used to login into GeoServer from the Google chrome internet browser. A new workspace 'unza_web' was created and a vector data source was added from the PostGIS database. The projection parameters for the GIS layers matching the shapefile coordinate system were input.

\subsection{Web map layers}

The layers to be published were enabled and then previewed in the Layer Preview Tab which supports a variety of output formats for data sharing. The formats are categorised into three types Applications (Google Earth, OpenLayers, GeoExplorer), WMS format (KML, GeoTiff, JPEG, PDF, etc.), WFS formats (CSV, GeoJSON, GML, JSON, etc.). The figure 12 shows a preview of the layers in open layers while figure 13 shows the layers in Geoexplorer

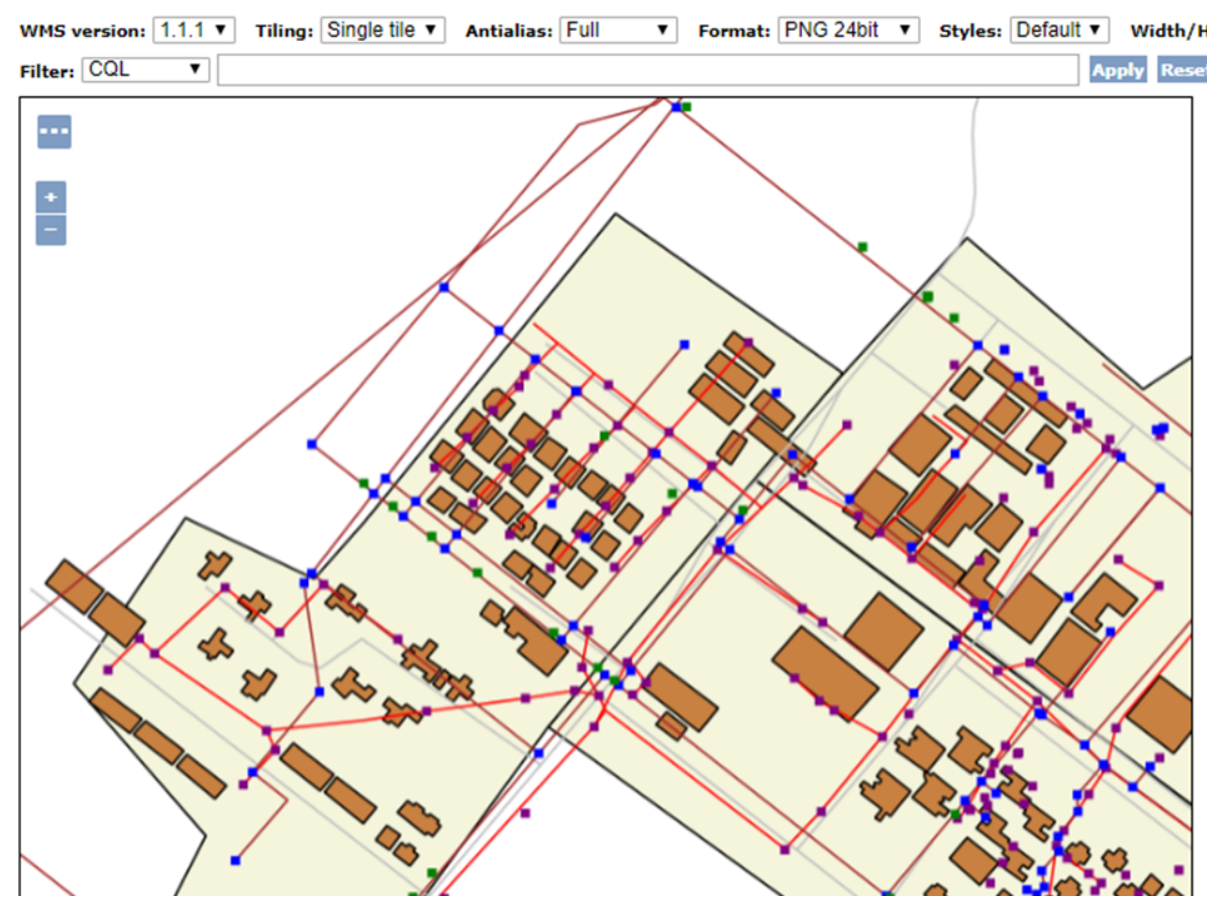

Fig. 12. Water and Sewer Network layers in open layers 


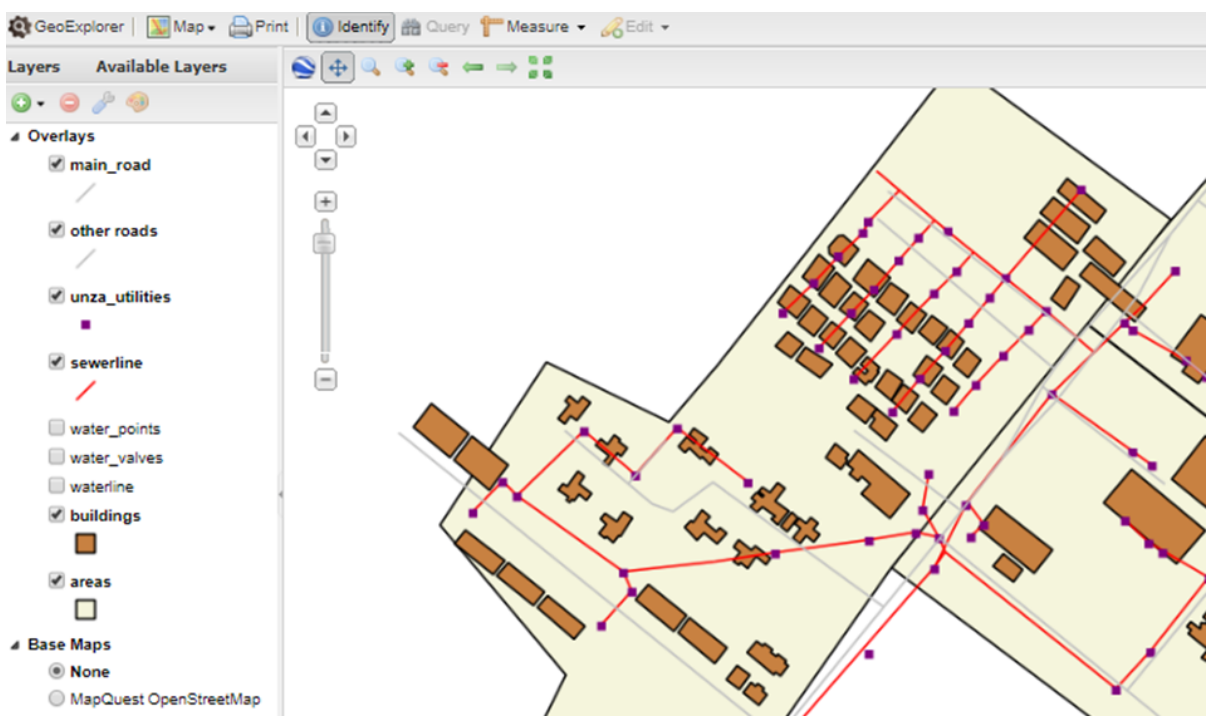

Fig. 13. Water and Sewer Network layers in Geoexplorer

\subsection{The web GIS portal}

The complete WebGIS portal which was to be the main access for users to the university GIS utility data was developed. Access to data and services was designed to require a user name and user password. The password had to be alphanumeric with a minimum of six characters. Access could also be obtained from scanning the QR code which gave the name of the structure as a link and in turn it displayed the web map.

\subsection{Sensor integration}

The water level sensors were installed on a few manholes and using Arduino Development Kit and internet of things, the sensors were connected to the web app. The series of sensor network were connected to a personal area network and an aggregator that has a GSM shield. This GSM shield will support the common mobile network technologies such as GSM, 3G, LTE. The GSM shield was connected to an Arduino aggregator and an operating system was used in order to communicate with the shield and upload data to a remote server. A cloud based service was used as a broker to gather all the information from the remote sensors, the most popular open source broker being the Mosquito server was proposed in the system. The sensor was designed to be able to send notification to the web app and the user could tell which manhole is affected prior to going to the field. The users could log in and view any information required for each structure. Administrator rights were also included to allow top management to be able to edit, update and manipulate the data as required. 


\section{Conclusion}

The WebGIS tools were used to build a working prototype of the spatial framework for the University of Zambia. Data was collected from various sources, analysed and processed and finally used to build a spatial Database using PostGiS and PostgreSQL and a Web Map. Using internet of things sensors were integrated into the web based framework after coding and tagging was done for each feature using QR coding system. It is envisioned the developed prototype will ease operations for the Resident Engineer in terms of maintenance, management and overall workflows.

\section{Recommendations}

The system can be greatly improved if accurate elevations of the water and sewer lines are known. At the moment the accurate locations are in the horizontal i.e. $\mathrm{X}$ and Y. A topographic survey of the entire corridor of the sewer and water lines could be done and an accurate digital terrain model can be generated and uploaded to the system hence improving the surface accuracy. In addition a scan of the lines of the water and sewer lines can be done using Ground Penetrating Radar (GPR). This would give precise elevations of the top of the pipes which can also be included into the system. Accurate information of both the ground elevation the pipe elevations can help when making new installations and can prevent damage of pipes as a result of any excavations within the University.

\section{$7 \quad$ Acknowledgements}

We would like to thank the University of Zambia Resident Engineer's office for their assistance, Department of Computer Science, School of Geography and School of Engineering for the advice and expertise rendered in this study.

\section{$8 \quad$ References}

[1] UNZA PRESS - The University of Zambia, "Strategic Plan 2018-2022" The Strategic Planning Office of the University of Zambia. P.O. Box 32379, LUSAKA 10101, ZAMBIA, 2018. https://doi.org/10.18697/ajfand.80.16275

[2] GIS Landmark, "Utility Mapping” Accessed [online] http://www.gislandmark.com/utilitymapping. Retrieved on 5th April, 2019.

[3] CPHEEO, Government of India, Ministry of Housing and Urban Affairs. "Manual on water supply and treatment". Accessed [online] http://mohua.gov.in/publication/manualon-water-supply-and-treatment-systems-cpheeo-1999.php. Retrieved on 22nd March, 2019. .

[4] PostgreSQL. (2018). About: PostgreSQL. Retrieved June 10, 2018, from PostgreSQL: https://www.postgresql.org/about/ https://doi.org/10.3139/9783446456419.fm

[5] OpenLayers. (2018). Home: OpenLayers. Retrieved July 20, 2018, from OpenLayers: https://openlayers.org/ https://doi.org/10.7287/peerj.preprints.27858/supp-9 
[6] Tomcat-Apache. (2018). Home: Apache Tomcat. Retrieved July 28, 2018, from Apache Tomcat: http://tomcat.apache.org/ https://doi.org/10.1007/978-1-4302-0378-0_2

[7] Hazael Phiri, Douglas Kunda and Jackson Phiri. "An IoT Smart Broiler Farming Model for Low Income Farmers" International Journal of Recent Contributions from Engineering, Science \& IT (iJES) - Vol. 6, No. 3, 2018, http://www.i-jes.org, 2018. https://doi.org/10.3991/ijes.v6i3.9287

[8] Tzounis, N. Katsoulas, T. Bartzanas and C. Kittas, "Internet of Things in agriculture, recent advances and future challenges," Biosystems Engineering, vol. 164, pp. 31-48, 2017. https://doi.org/10.1016/j.biosystemseng.2017.09.007 https://doi.org/10.1016/j. biosystemseng.2017.09.007

[9] M. Hossain, M. Fotouhi and R. Hasan, "Towards an Analysis of Security Issues, Challenges, and Open Problems in the Internet of Things," IEEE World Congress on Services, 2015. https://doi.org/10.1109/services.2015.12

[10] M. A. Mahmood, W. K. G. Seah and I. Welch, "Reliability in Wireless Sensor Networks: A Survey and Challenges Ahead," Computer Networks, 2014. https://doi.org/10.10 16/j.comnet.2014.12.016

[11] O. A. Chase, J. F. Sousa de Almeida, J. R. Brito de Souza and C. T. da Costa Junior, "Sensory platform architecture for IN SITU monitoring the thermal comfort in rural environments - The case study at Federal Rural University of Amazonian, Brazil," Measurement, Elsevier, vol. 58, pp. 294-300, https://doi.org/10.1016/j.measurement. 2014. https://doi.org/10.1016/j.measurement.2014.08.031

[12] M. F. Othman and K. Shazali, "Wireless Sensor Network Applications: A Study in Environment Monitoring System," International S ymposium on R obotics and Intelligent Sensors, Procedia Engineering, Elsevier, vol. 41, pp. 1204-1210 https://doi.org/ 10.1016/j.proeng. 2012. https://doi.org/10.1016/j.proeng.2012.07.302

[13] Black Duck Software, Inc. (Open Hub) (2019). "SAS.Planet Open Hub Project" 800 District Ave Burlington, MA 01803. [online] https://www.openhub.net/p/sasplanet

[14] Amazon Web Services, Inc. “AWS Tagging Strategies” https://aws.amazon.com/answers/ account-management/aws-tagging-strategies/

[15] DENSO Wave, 2019. Barcode/QR Code/RFID, "What is a barcode?" [online] https://www.denso-wave.com/en/adcd/fundamental/barcode/barcode/index.html accessed on 10th May, 2019.

[16] Natasha Mwansa Kachingwe and Jackson Phiri (2018) "Real-Time Data Capture Model for Accelerated Payment of Small-Scale Farmers" American Journal of Engineering and Applied Sciences 2018, 11 (3): 1164.1177. https://doi.org/10.3844/ajeassp.2018.1164.1177

[17] Code, Q.R., 2011. Q R code.com. https://www.qrcode.com/en/about/standards.html

[18] ISO/IEC, 2006. "Information technology automatic identification and data capture techniques -Barcode symbology QR code". Switzerland.

[19] Singh, S., 2016. QR code analysis. Int. J. Adv. Res. Comput. Sci. Software Eng., 6: 89-92.

[20] Okello, N., Banda, F. \& Tembo, E., “WebGIS for Water Utility Management”. Imperial Journal of Interdisciplinary Research (IJIR), 3(8), pp. 1-6, 2017

[21] Sipiwe Chihana, Jackson Phiri and Douglas Kunda, "An IoT based Warehouse Intrusion Detection (E-Perimeter) and Grain Tracking Model for Food Reserve Agency" (IJACSA) International Journal of Advanced Computer Science and Applications, Vol. 9, No. 9, 2018. https://doi.org/10.14569/ijacsa.2018.090929

[22] Júlio Gabriel Chilela, "Web Geographic Information Systems (Webgis) For Smart Campus and Facility Management" Mathematics of Faculty of Science and Technology at University of Coimbra, Portugal, 2016. 
[23] Natasha Mwansa Kachingwe and Jackson Phiri, "Real-Time Data Capture Model for Accelerated Payment of Small-Scale Farmers" American Journal of Engineering and Applied Sciences 2018, 11 (3): 1164.1177. https://doi.org/10.3844/ajeassp.2018.1164.1177

[24] Mulima Chibuye and Jackson Phiri , "A Remote Sensor Network using Android Things and Cloud Computing for the Food Reserve Agency in Zambia" (IJACSA) International Journal of Advanced Computer Science and Applications, Vol. 8, No. 11, 2017. https://doi.org/10.14569/ijacsa.2017.081150

[25] Fujitsu Laboratories Ltd, "Fujitsu Develops Technology for Low-Cost Detection of Potential Sewer System Overflows" Accessed [online], http://www.fujitsu. com/global/about/resources/news/press-releases/2015/0210-03.html, Retrieved on 15th June, 2018. https://doi.org/10.29268/stcc.2013.0002

[26] Brian M. Mutale and Jackson Phiri (2016). "Web Based Document Archiving Using Time Stamp and Barcode Technologies - A Case of the University of Zambia" International Journal of Innovative Research in Science, Engineering and Technology (An ISO 3297: 2007 Certified Organization) Vol. 5, Issue 4, April 2016.

\section{Authors}

Mr. Gabriel Chibuye is experienced in various types of Land Surveying and Geographical Information Systems (GIS ) Services. Knowledgeable in the design and construction of roads, bridges, and other structures. He has done his Masters in Geoinformation Science and Earth Observation from The University of Zambia.

Article submitted 2020-01-07. Resubmitted 2020-03-02. Final acceptance 2020-03-04. Final version published as submitted by the authors. 